J. Lake Sci. (湖泊科学) , 2018, 30(3): 713-722

DOI 10. 18307/2018. 0313

(c) 2018 by Journal of Lake Sciences

\title{
淮南采煤塌陷湖泊浮游植物优势种的营养动力学”
}

\author{
张 鍂 ${ }^{1}$, 易齐涛 ${ }^{1,3 * *}$, 谢 凯 ${ }^{2}$, 张思亮 ${ }^{1}$, 余艳霞 ${ }^{1}$, 张 银 $^{1}$ \\ ( 1 : 安徽理工大学地球与环境学院,淮南 232001) \\ (2: 安徽理工大学数学与大数据学院, 淮南 232001) \\ (3: 中国科学院生态环境研究中心, 北京 100085)
}

\begin{abstract}
摘 要: 在淮南潘谢矿区选取 3 个营养盐结构差异较大的塌陷湖泊, 于 2014- 2015 年 4 个季度分别对浮游植物群落结构 组成进行调查, 选取 3 个湖泊中的优势种 (属) 具尾蓝隐藻 (Chroomonas caudata)、链形小环藻 (Cyclotella catenata) 和伪鱼 腥藻 (Pseudanabaena sp.) 作为研究对象, 设置不同的氮 $(\mathrm{N})$ 、磷 $(\mathrm{P})$ 浓度梯度进行营养动力学培养实验, 并结合 Monod 方 程, 获得 3 个藻种在不同营养盐限制下的营养动力学参数. $\mathrm{N}$ 限制下具尾蓝隐藻、小环藻和伪鱼腥藻的最大生长速率 $\left(\mu_{\text {max }}\right)$ 和半饱和常数 $(K s)$ 分别为: $0.66 \mathrm{~d}^{-1} 、 1.66 \mathrm{mg} / \mathrm{L} ; 0.37 \mathrm{~d}^{-1} 、 1.06 \mathrm{mg} / \mathrm{L} ; 0.71 \mathrm{~d}^{-1} 、 2.26 \mathrm{mg} / \mathrm{L} ; \mathrm{P}$ 限制下它们的 $\mu_{\text {max }}$ 和 $K s$ 则分别为: $0.51 \mathrm{~d}^{-1} 、 0.023 \mathrm{mg} / \mathrm{L} ; 0.31 \mathrm{~d}^{-1} 、 0.035 \mathrm{mg} / \mathrm{L} ; 0.90 \mathrm{~d}^{-1} 、 0.015 \mathrm{mg} / \mathrm{L}$. 综上所述, 在 $\mathrm{N}$ 充足时, 伪鱼腥藻能够在竞争 中形成优势, 同时在 $\mathrm{P}$ 限制情况下易成为优势种, 从营养动力学的角度揭示了其在塌陷湖泊中占据优势的营养盐动力学 机制. 研究结果可以为沉陷区水域开发利用和营养盐管理提供科学依据.
\end{abstract}

关键词: 采煤塌陷区; 塌陷湖泊;浮游植物; 营养动力学;营养限制

\section{Nutrient kinetics of dominant species of phytoplankton in the artificial lakes formed from land subsidence by mining activities in the Huainan coalmine subsidence areas}

\author{
ZHANG Xin ${ }^{1}$, YI Qitao ${ }^{1,3 * *}$, XIE Kai ${ }^{2}$, ZHANG Siliang ${ }^{1}$, YU Yanxia ${ }^{1} \&$ ZHANG Yin $^{1}$ \\ (1: School of Earth and Environment, Anhui University of Science and Technology, Huainan 232001, P.R.China) \\ (2: School of Mathematics and Big Data, Anhui University of Science and Technology, Huainan 232001, P.R. China) \\ (3: Research Center for Eco-environmental Sciences, Chinese Academy of Sciences, Beijing 100085, P.R.China)
}

Abstract: Three lakes in the Huainan Panxie coalmine areas, with different nutrient ratio, were investigated for their phytoplankton communities in four seasons from 2014 to 2015. Three dominant species (genera) of phytoplankton, including Chroomonas caudata, Cyclotella catenata and Pseudanabaena sp., were selected to obtain their nutrient kinetics by a number of incubation experiments with limitation for individual nitrogen $(\mathrm{N})$ and phosphorus $(\mathrm{P})$. Under $\mathrm{N}$ limitation conditions, the maximum specific growth and half-saturated constant for the three species of Chroomonas caudate, Cyclotella catenata and Pseudanabaena sp. were $0.66 \mathrm{~d}^{-1}$ and $1.66 \mathrm{mg} / \mathrm{L}, 0.37 \mathrm{~d}^{-1}$ and $1.06 \mathrm{mg} / \mathrm{L}, 0.71 \mathrm{~d}^{-1}$ and $2.26 \mathrm{mg} / \mathrm{L}$, respectively; with respect of $\mathrm{P}$ limitation conditions, they were $0.51 \mathrm{~d}^{-1}$ and $0.023 \mathrm{mg} / \mathrm{L}, 0.31 \mathrm{~d}^{-1}$ and $0.035 \mathrm{mg} / \mathrm{L}, 0.90 \mathrm{~d}^{-1}$ and $0.015 \mathrm{mg} / \mathrm{L}$, respectively. Especially, the Pseudanabaena sp. takes dominant role due to its nutrient competition ability under $\mathrm{P}$ limitation in this type of lakes, where $\mathrm{N}$ is sufficient for its growth. This research has important implication on local nutrient management of water resources in the coal mine areas.

Keywords: Coalmine subsidence areas; subsidence lakes; phytoplankton; nutrition kinetics; nutrient limitation

淮南煤矿近几十年来由于煤炭的大量开采, 导致了大面积的土地沉陷和积水, 形成了许多小型塌陷湖 泊组成的水生态景观. 研究资料表明 2010 年淮南矿区土地沉陷面积达 $140 \mathrm{~km}^{2}$, 至 2020 年将进一步扩展至 $200 \mathrm{~km}^{2}$, 其中水域面积占 30\% 50\%, 在矿区社会经济发展和生态环境保护中具有十分重要的作用 ${ }^{[1]}$,因而

* 国家自然科学基金项目 (51579001,51504012) 和中国博士后科学基金项目(2014M560127)联合资助. 2017-07-04 收稿;2017-08-13 收修改稿. 张金金( 1994 ), 女, 硕士研究生; E-mail:418849804@ qq.com.

** 通信作者; E-mail:yiqitao@163.com. 
对其生态系统结构和功能的研究具有十分重要的意义.

浮游植物是生态系统的主要初级生产者和食物网的起点, 也是生物与环境因子相互作用的第一个重要 界面, 其群落结构组成和演替规律对区域生态环境特征具有重要的指示作用, 同时对生态系统营养结构和 功能起着基础性的调控作用 ${ }^{[2]}$. 目前, 涉及采煤塌陷湖泊中浮游植物群落结构与环境因子关系的研究较多, 相关研究表明影响淮南采煤塌陷湖泊浮游植物群落结构的主要环境因子为光照、水温和营养盐 ${ }^{[3]}$, 影响淮 北采煤塌陷湖泊浮游植物群落结构演替的主要环境因子包括营养盐浓度和温度等 ${ }^{[4]}$. 本研究在分析淮南采 煤塌陷湖泊浮游植物群落结构的基础上, 选择其中的优势种, 在不同氮 (N)、磷 (P) 浓度梯度下进行营养限 制培养实验, 并用 Monod 方程确定其营养盐动力学参数. 本研究拟结合浮游植物群落结构野外调查结果和 室内营养动力学实验, 深人分析该类型湖泊优势物种形成和演替规律的动力学机制, 以期获得更加准确可 靠的结论,为本研究区的营养盐管理提供科学依据.

\section{1 材料与方法}

\section{1 研究区域与站点}

淮南潘谢矿区 $\left(32^{\circ} 42^{\prime} 23^{\prime \prime} \sim 32^{\circ} 55^{\prime} 38^{\prime \prime} \mathrm{N}, 116^{\circ} 18^{\prime} 32^{\prime \prime} \sim 116^{\circ} 57^{\prime} 05^{\prime \prime} \mathrm{E}\right)$ 是淮南煤矿基地中沉陷积水最为集中 的区域, 位于安徽省淮河北岸冲积平原, 矿区东西长近 $58 \mathrm{~km}$, 南北宽 $6 \sim 25 \mathrm{~km}$, 面积约 $865 \mathrm{~km}^{2}$. 矿区内天然 河道包括西汁河、港河、黑河、济河、泥河和架河, 人工河道有永辛河, 均由西北向东南流人淮河 ${ }^{[5]}$, 自西向东 分为西沜河、永幸河、架河和泥黑河 4 个小流域. 在潘谢矿区东部的潘集矿区、中部的顾桥矿区和西部的谢 桥矿区范围内各选 1 个采煤塌陷湖泊进行研究 (图 1), 分别命名为潘谢潘集 (PXPJ)、潘谢顾桥 (PXGQ) 和 潘谢谢桥 (PXXQ). 这 3 个湖泊水文条件差异较大, 其中 PXPJ 站点位于潘集矿区西北侧, 与流经矿区的泥 河常年相通, 属于泥河小流域; PXGQ 站点位于顾桥矿区西北侧 (永幸河小流域), 但水体相对封闭; PXXQ 站 点则位于谢桥矿的西北侧, 在汛期通过节制闸接纳位于其南边的济河季节性引水. 3 个湖泊用于渔业养殖 地,每年有鱼苗投人,但一般无饵料施加, 湖泊的形成年龄、容积、水深和面积等具体信息见文献 $[6]$.

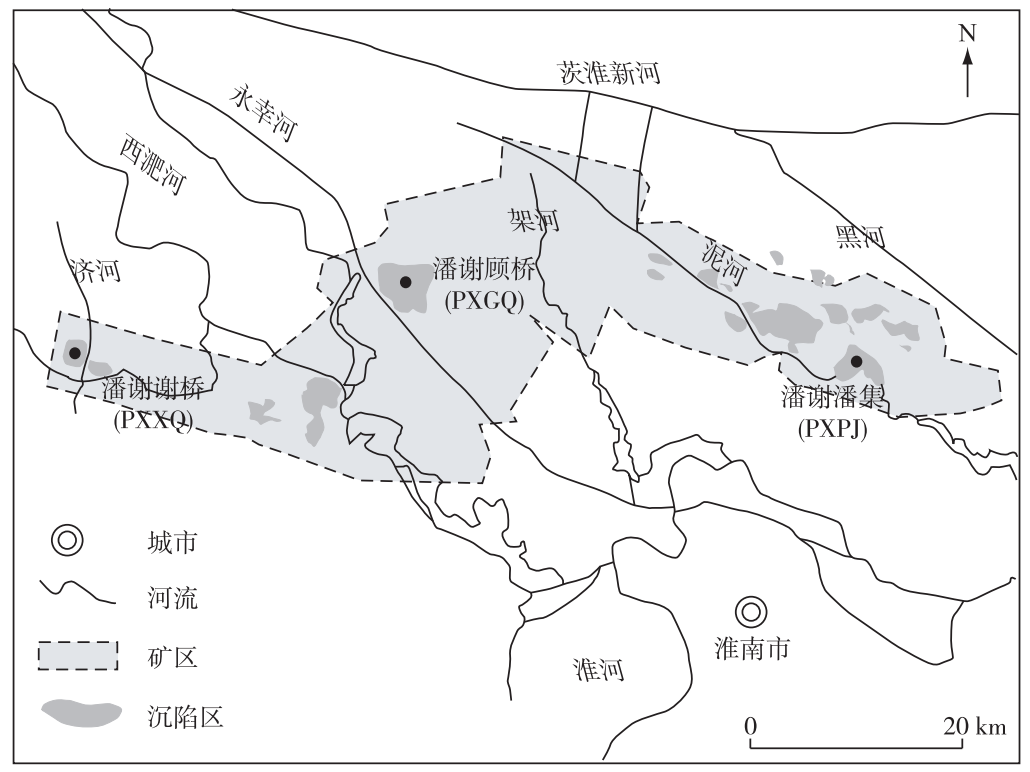

图 1 潘谢采煤沉陷区研究湖泊站点分布

Fig.1 Distribution of the subsidence areas and location of three studied lakes in the Panxie coalmine area

\section{2 水质、浮游植物样品采集与分析}

于 2014-2015 年分 4 个季度对 PXPJ、PXGQ 和 PXXQ 3 个湖泊的水质特征和浮游植物群落结构进行调 
查和分析. 在各湖泊中心附近设置 3 个水质采样点, 用有机玻璃采水器采集表层水样. 水质调查和分析指标 包括: 水温 $(\mathrm{Tem}) 、 \mathrm{pH}$ 、透明度 $(\mathrm{SD})$ 、电导率 $(\mathrm{EC})$ 、溶解氧 ( DO) 、总悬浮颗粒物 ( TSP)、碱度 (Alk)、溶解性反 应磷 $\left(\mathrm{PO}_{4}^{3-}-\mathrm{P}\right)$ 、硝态氮 $\left(\mathrm{NO}_{3}^{-}-\mathrm{N}\right)$ 、化学需氧量 $\left(\mathrm{COD}_{\mathrm{Cr}}\right)$ 、总氮 $(\mathrm{TN})$ 、总磷 $(\mathrm{TP})$ 和叶绿素 $\mathrm{a}(\mathrm{Chl} . \mathrm{a})$. 其中分别 使用 $\mathrm{pH}$ 计 ( YSI $\mathrm{pH} 100$ ) 、JPB-607A 便携式溶解氧测定仪、塞氏盘和 DDS-11A 电导率仪对 $\mathrm{pH} 、 \mathrm{DO}$ 浓度、SD 和 EC 进行现场测定. 参照相关国家标准, TSP 采用重量法测定,碱度采用酸碱指示剂滴定法测定, $\mathrm{PO}_{4}^{3-}-\mathrm{P}$ 浓 度采用锄兰分光光度法测定, $\mathrm{NO}_{3}^{-}-\mathrm{N}$ 浓度采用紫外分光光度法测定, $\mathrm{TN}$ 浓度采用碱性过硫酸钾消解一紫外 分光光度法测定, $\mathrm{TP}$ 浓度采用过硫酸钾消解一锄酸铵分光光度法测定, $\mathrm{COD}_{\mathrm{Cr}}$ 采用重铬酸钾法测定 ${ }^{[7]}$. Chl.a 浓度采用分子菼光法测定 ${ }^{[8]}$. 选取 SD、TN、TP 和 Chl.a 共 4 个指标计算湖泊营养状态综合指数 $(T L I)$, 具体 计算公式参见文献 $[9]$.

浮游植物采样点和水质采样点一致, 定性样品用 $25^{\#}$ (网孔直径 $64 \mu \mathrm{m}$ ) 浮游生物网在水面下 $0.5 \mathrm{~m}$ 处以 “ $\infty$ ” 字型来回捞取, 加鲁哥试剂固定, 部分样品作活体观察, 用于鉴定种类. 定量样品用 $5.0 \mathrm{~L}$ 采水器根据水 深采集上、中、下层水样混合后装人 $1000 \mathrm{ml}$ 采集瓶, 现场加人 $15 \mathrm{ml}$ 鲁哥试剂固定, 带回实验室静置沉淀 48 $\mathrm{h}$ 并浓缩至 $50 \mathrm{ml}$. 计数前摇匀后取 $0.1 \mathrm{ml}$ 在 $20 \mathrm{~mm} \times 20 \mathrm{~mm}$ 的计数框内鉴定和计数, 计数方法采用视野法, 对于群体性藻类如铜绿微囊藻 (Microcystis aeruginosa) 等, 以细胞数计数,具体参照文献 [10].

\section{3 营养动力学实验}

在对 4 个季节浮游植物群落结构分析的基础上, 选取不同门类的浮游植物优势种进行营养动力学实 验, 分别为具尾蓝隐藻 (Chroomonas caudata)、链形小环藻 (Cyclotella catenata) 和伪鱼腥藻 (Pseudanabaena sp. ), 在不同 N、P 浓度的培养基进行营养限制培养. 藻种均购于中国科学院水生生物研究所, 培养基具体配 方参见中国淡水藻种库官网, 其中具尾蓝隐藻采用 BBM 培养基, 链形小环藻采用 CSI 培养基, 伪鱼腥藻采用 BG-11 培养基.

实验前将各藻种扩大培养 1 周, 再饥饿培养 $2 \mathrm{~d}$ 后取一定体积的藻种以 4000 转/ $\mathrm{min}$ 离心 $8 \mathrm{~min}$, 去掉上 清液, 用 $15 \mathrm{mg} / \mathrm{L}$ 的 $\mathrm{NaHCO}_{3}$ 洗涤后离心, 去上清液, 此过程重复 3 次, 然后用无菌水稀释至一定的密度用于 接种和实验. 实验中所有玻璃器血均用稀盐酸浸泡过夜并用去离子水洗涤, 培养基均用高压灭菌锅在 $121^{\circ} \mathrm{C}$ 下灭菌 $0.5 \mathrm{~h}^{[11]}$.

采用动力学 “分批培养实验”,每组设置 3 个平行. 以各藻种培养基为基础配制成无 $\mathrm{N}$ 或无 $\mathrm{P}$ 培养基, 然 后分别加人系列浓度的营养盐 $\left(\mathrm{NaNO}_{3}\right.$ 或 $\left.\mathrm{K}_{2} \mathrm{HPO}_{4}\right)$, 具体 $\mathrm{N} 、 \mathrm{P}$ 浓度在范围内倍比梯度设置见表 1 , 最高浓度 一般设置为实际水体的 $2 \sim 3$ 倍, 其中 P 高浓度添加不超过 PXGQ 站点水体 P 的浓度范围. 取配置好的各组 培养基 $100 \mathrm{ml}$ 置于 $250 \mathrm{ml}$ 三角瓶中, 接种对应藻种后置于光照培养箱(GZX-400BS-III) 中静置培养, 温度设 置为 $25^{\circ} \mathrm{C}$, 光照强度为 $4000 \mathrm{~lx}$, 光暗比为 $12 \mathrm{~h}: 12 \mathrm{~h}$, 每天定时晃瓶 $3 \sim 4$ 次, 并定时取少量样品在显微镜下进 行藻细胞计数, 其中伪鱼腥藻为丝状蓝藻并容易聚团, 在计数前稀释并用超声波震荡离散后再进行计数. 在 培养后期, 3 组平行实验中至少两组藻类增长率低于 $5 \%$ 时认为藻类达到最大生物量并终止培养.

表 13 种优势种藻类培养实验添加的氮、磷浓度

Tab.1 Added nitrogen and phosphorus concentrations for phytoplankton nutrient kinetics experiment

\begin{tabular}{ccccccccccc}
\hline 培养藻种 & 营养盐 & \multicolumn{7}{c}{ 添加浓度/ $(\mathrm{mg} / \mathrm{L})$} \\
\hline 具尾蓝隐藻 & $\mathrm{P}$ & 0 & 0.01 & 0.02 & 0.04 & 0.08 & 0.16 & 0.32 & 0.64 \\
& $\mathrm{~N}$ & 0 & 0.20 & 0.40 & 0.80 & 1.60 & 3.20 & 6.40 & 12.8 \\
链形小环藻 & $\mathrm{P}$ & 0 & 0.01 & 0.02 & 0.04 & 0.08 & 0.16 & 0.32 & 0.64 \\
& $\mathrm{~N}$ & 0 & 0.20 & 0.40 & 0.80 & 1.60 & 3.20 & 6.40 & 12.8 \\
伪鱼腥藻 & $\mathrm{P}$ & 0 & 0.01 & 0.02 & 0.04 & 0.08 & 0.16 & 0.32 & 0.64 \\
& $\mathrm{~N}$ & 0 & 0.20 & 0.40 & 0.80 & 1.60 & 3.20 & 6.40 & 12.8 \\
\hline
\end{tabular}

\section{4 数据分析方法}

用浮游植物优势种的优势度指数 $(Y)$ 来确定浮游植物优势种, 其计算公式为: 


$$
Y=\frac{n_{i}}{N} \cdot f_{i}
$$

式中, $Y$ 为优势度指数, $n_{i}$ 为各站点 $i$ 物种的个数, $N$ 为各站点浮游植物总个数, $f_{i}$ 为 $i$ 物种在各站位中出现的 频率. 当 $Y>0.02$ 时,该物种为群落中的优势种.

生物量测定采用血球计数板计数法进行, 特定增长率 $(\mu)$ 指在某一时间间隔内藻类生长速率 ${ }^{[1]}$, 计算 公式为:

$$
\mu=\ln \left(X_{2} / X_{1}\right) /\left(t_{2}-t_{1}\right)
$$

式中, $X_{2}$ 为某一时间间隔终结时的藻类现存量, $X_{1}$ 为某一时间间隔开始时的藻类现存量, $t_{2}-t_{1}$ 为时间间隔. 将 Monod 方程式 $\mu=\mu_{\max } \cdot c /(c+K s)$ 变成以下形式进行动力学参数计算 ${ }^{[12]}$ :

$$
\frac{1}{\mu}=\frac{K s}{\mu_{\max }} \cdot \frac{1}{c}+\frac{1}{\mu_{\max }}
$$

式中, $\mu$ 为比生长速率, $\mu_{\max }$ 为最大比生长速率, $c$ 为限制性基质浓度 $(\mathrm{mg} / \mathrm{L}), K s$ 为半饱和常数 $(\mathrm{mg} / \mathrm{L})$. 以 $1 / \mu$ 和 $1 / c$ 做图, 通过线性回归求得 $\mu_{\max }$ 和 $K s$ 值.

\section{2 研究结果}

\section{1 湖泊水质特征}

调查期间, PXPJ 站点水体 TP、TN 和 Chl.a 浓度变化范围分别为 $0.05 \sim 0.10 \mathrm{mg} / \mathrm{L} 、 1.4 \sim 4.1 \mathrm{mg} / \mathrm{L}$ 和 $6.5 \sim$ $43.0 \mathrm{mg} / \mathrm{m}^{3}$; PXGQ 站点这 3 个指标变化范围分别为 $0.14 \sim 0.63 \mathrm{mg} / \mathrm{L} 、 1.4 \sim 4.7 \mathrm{mg} / \mathrm{L}$ 和 $3.2 \sim 63.7 \mathrm{mg} / \mathrm{m}^{3}$; PXXQ 站点则分别为 $0.03 \sim 0.08 \mathrm{mg} / \mathrm{L} 、 1.2 \sim 4.5 \mathrm{mg} / \mathrm{L}$ 和 $10.5 \sim 40.8 \mathrm{mg} / \mathrm{m}^{3}$ (表 2). 总体来看, 3 个湖泊水体 $\mathrm{N} 、 \mathrm{P}$ 和 Chl.a 浓度均较高, 体现了富营养化湖泊的典型特征.

\begin{tabular}{|c|c|c|c|c|c|c|c|c|c|c|c|c|}
\hline \multirow{2}{*}{ 水质指标 } & \multicolumn{4}{|c|}{ PXPJ } & \multicolumn{4}{|c|}{ PXGQ } & \multicolumn{4}{|c|}{ PXXQ } \\
\hline & 春季 & 夏季 & 秋季 & 冬季 & 春季 & 夏季 & 秋季 & 冬季 & 春季 & 夏季 & 秋季 & 冬季 \\
\hline $\mathrm{Tem} /{ }^{\circ} \mathrm{C}$ & 18.5 & 29.3 & 18.6 & 4.6 & 21.5 & 33.7 & 17.5 & 5.3 & 20.0 & 30.3 & 17.9 & 3.3 \\
\hline $\mathrm{EC} /(\mu \mathrm{S} / \mathrm{cm})$ & 757 & 580 & 585 & 524 & 427 & 620 & 506 & 429 & 977 & 723 & 617 & 540 \\
\hline $\mathrm{SD} / \mathrm{m}$ & 1.2 & 0.7 & 1.0 & - & 0.7 & 0.6 & 0.6 & - & 1.1 & 0.7 & 0.9 & 1.3 \\
\hline $\mathrm{pH}$ & 9.38 & 8.23 & 7.46 & 7.64 & 9.21 & 8.84 & 8.36 & 7.67 & 9.20 & 8.36 & 7.57 & 7.66 \\
\hline $\mathrm{DO} /(\mathrm{mg} / \mathrm{L})$ & 8.08 & 11.10 & 5.33 & 11.50 & 7.88 & 14.83 & 6.90 & 11.1 & 7.68 & 15.36 & 5.86 & 10.83 \\
\hline $\mathrm{TSS} /(\mathrm{mg} / \mathrm{L})$ & 5.7 & 7.0 & 4.3 & 8.0 & 10.3 & 12.7 & 3.7 & 9.0 & 3.3 & 12.7 & 6.8 & 3.0 \\
\hline $\mathrm{COD}_{\mathrm{Cr}} /(\mathrm{mg} / \mathrm{L})$ & 21.7 & 19.7 & 22.2 & 24.7 & 36.9 & 26.6 & 29.8 & 24.7 & 20.5 & 16.7 & 23.0 & 21.7 \\
\hline $\mathrm{Alk} /(\mathrm{mg} / \mathrm{L})$ & 248 & 134 & 189 & 189 & 151 & 111 & 130 & 143 & 266 & 142 & 194 & 217 \\
\hline $\mathrm{TP} /(\mathrm{mg} / \mathrm{L})$ & 0.08 & 0.10 & 0.07 & 0.05 & 0.26 & 0.63 & 0.52 & 0.14 & 0.06 & 0.08 & 0.06 & 0.03 \\
\hline $\mathrm{TN} /(\mathrm{mg} / \mathrm{L})$ & 4.1 & 1.6 & 1.4 & 2.3 & 4.7 & 1.4 & 2.1 & 2.0 & 4.5 & 1.2 & 1.2 & 1.5 \\
\hline $\mathrm{NO}_{3}^{-}-\mathrm{N} /(\mathrm{mg} / \mathrm{L})$ & 1.04 & 0.35 & 0.49 & 1.42 & 0.64 & 0.17 & 0.80 & 1.34 & 1.75 & 0.09 & 0.19 & 0.93 \\
\hline $\mathrm{PO}_{4}^{3-}-\mathrm{P} /(\mathrm{mg} / \mathrm{L})$ & 0.006 & 0 & 0.031 & 0.001 & 0.117 & 0.481 & 0.428 & 0.090 & 0.007 & 0 & 0.010 & 0 \\
\hline Chl.a/ $\left(\mathrm{mg} / \mathrm{m}^{3}\right)$ & 21.8 & 43.0 & 7.3 & 6.5 & 63.7 & 30.9 & 30.8 & 3.2 & 10.5 & 40.8 & 16.6 & 11.2 \\
\hline
\end{tabular}

表 2 调查期间淮南潘谢采煤沉陷区内 3 个塌陷湖泊的水质指标

Tab.2 Seasonal water quality of the three lakes in the Huainan Panxie coalmine area

\section{2 湖泊浮游植物群落结构特征}

调查期间, 3 个湖泊共观察到浮游植物 7 门 51 属 88 种, 其中绿藻门种类最多, 共 43 种, 占浮游植物总 种数的 $48.8 \%$; 其次是蓝藻, 共 21 种, 占浮游植物总种数的 $23.9 \%$; 硅藻 17 种, 占总种数的 $19.3 \%$; 甲藻 4 种, 占总种数的 $4.5 \%$; 裸藻 2 种, 占总种数的 $2.3 \%$ (图 2).

PXPJ 站点春季的第 1 优势种 (属) 为尖针杆藻, 优势度为 0.199 , 第 2 优势种 (属) 为伪鱼腥藻 (优势度为 0.180 ) ; 夏、秋和冬季第 1 优势种 (属) 分别为具尾蓝隐藻、小环藻和具尾蓝隐藻, 优势度分别为 $0.215 、 0.224$ 和 0.372. PXGQ 站点春、冬季第 1 优势种 (属) 为具尾蓝隐藻, 优势度分别为 0.559 和 0.250 ; 夏、秋季第 1 优 
势种 (属) 为伪鱼腥藻, 优势度分别为 0.412 和 $0.528 . P X X Q$ 站点春季第 1 优势种 (属) 为具尾蓝隐藻, 优势度 为 0.244 ; 夏、秋季为伪鱼腥藻, 优势度分别为 0.510 和 0.473 ; 冬季为卵型隐藻,优势度为 0.375 (表 3 ).

表 3 PXPJ、PXGQ 和 PXXQ 湖泊水体中浮游植物优势种 ( 属) 名录及优势度分布 *

Tab.3 Dominant species of phytoplankton in the three lakes at sites PXPJ, PXGQ and PXXQ

\begin{tabular}{|c|c|c|c|}
\hline 季节 & PXPJ & PXGQ & PXXQ \\
\hline 春季 & $\begin{array}{l}\text { 尖针杆藻 Synedra acus }(0.199) \\
\text { 伪鱼腥藻属 Pseudanabaena }(0.180) \\
\text { 具尾蓝隐藻 Chroomonas caudata }(0.164) \\
\text { 卵形急藻 Cryptomonas ovata Ehr. }(0.121) \\
\text { 衣藻属 Chlamydomonas }(0.064) \\
\text { 曲壳藻属 Achnanthes }(0.053) \\
\text { 螺旋纤维藻 Ankistrodesmus spiralis }(0.051) \\
\text { 链形小环藻 Cyclotella catenata }(0.040) \\
\text { 小球藻属 Chlorella }(0.032)\end{array}$ & $\begin{array}{l}\text { 具尾蓝隐藻 Chroomonas caudata }(0.559) \\
\text { 卵形隐藻 Cryptomonas ovata }(0.105) \\
\text { 衣藻属 Chlamydomonas }(0.081) \\
\text { 链形小环藻 Cyclotella catenata }(0.073) \\
\text { 伪鱼腥藻属 Pseudanabaena }(0.038) \\
\text { 小球藻属 Chlorella }(0.027)\end{array}$ & $\begin{array}{l}\text { 具尾蓝隐藻 Chroomonas caudata }(0.244) \\
\text { 链形小环藻 Cyclotella catenata }(0.175) \\
\text { 尖针杆藻 Synedra acus }(0.101) \\
\text { 伪鱼腥藻属 Pseudanabaena }(0.077) \\
\text { 小球藻属 Chlorella }(0.070) \\
\text { 螺旋纤维藻 Ankistrodesmus spiralis }(0.057) \\
\text { 卵形隐藻 Cryptomonas ovata }(0.047) \\
\text { 四尾栅藻 Scenedesmus quadricauda }(0.043) \\
\text { 梅尼小环藻 Cyclotella meneghiniana }(0.020) \\
\text { 小型月牙藻 Selenastrum minutum }(0.020)\end{array}$ \\
\hline 夏季 & $\begin{array}{l}\text { 具尾蓝隐藻 Chroomonas caudata }(0.215) \\
\text { 伪鱼腥品喿属 Pseudanabaena }(0.183) \\
\text { 链形小环藻 Cyclotella catenata }(0.166) \\
\text { 卵形隐藻 Cryptomonas ovata }(0.089) \\
\text { 螺旋藻属 Spirulina }(0.079) \\
\text { 小球藻属 Chlorella }(0.058) \\
\text { 尖针杆藻 Synedra acus }(0.023) \\
\text { 简单罗马藻 Romeria simplet }(0.021)\end{array}$ & $\begin{array}{l}\text { 伪鱼腥藻属 Pseudanabaena }(0.412) \\
\text { 弯形小尖头藻 Raphidiopsis curvata }(0.123) \\
\text { 色球藻属 Chroococcus }(0.106) \\
\text { 链形小环藻 Cyclotella catenata }(0.081) \\
\text { 螺旋藻属 Spirulina }(0.041) \\
\text { 细小平裂藻 Merismopedia minima }(0.028) \\
\text { 尖针杆藻 Synedra acus }(0.025) \\
\text { 小球藻属 Chlorella }(0.024) \\
\text { 具尾蓝隐藻 Chroomonas caudata }(0.021) \\
\text { 卵形隐藻 Cryptomonas ovata }(0.021)\end{array}$ & $\begin{array}{l}\text { 伪鱼腥藻属 Pseudanabaena }(0.510) \\
\text { 弯形小尖头藻 Raphidiopsis curvata }(0.081) \\
\text { 具尾蓝隐藻 Chroomonas caudata }(0.069) \\
\text { 束丝藻属 Aphanizomenon }(0.057) \\
\text { 链形小环澡 Cyclotella catenata }(0.039) \\
\text { 衣藻属 Chlamydomonas }(0.032) \\
\text { 卵形隐藻 Cryptomonas ovata }(0.031) \\
\text { 尖针杆藻 Synedra acus }(0.027) \\
\text { 小球藻属 Chlorella }(0.020)\end{array}$ \\
\hline 秋季 & $\begin{array}{l}\text { 小环藻属 Cyclotella }(0.224) \\
\text { 卵形隐藻 Cryptomonas ovata }(0.192) \\
\text { 变异直链藻 Melosira varians }(0.087) \\
\text { 具尾蓝隐藻 Chroomonas caudata }(0.050) \\
\text { 伪鱼腥藻属 Pseudanabaena }(0.050) \\
\text { 衣藻属 Chlamydomonas }(0.037) \\
\text { 肘状针杆藻 Synedra ulna }(0.037) \\
\text { 双对栅藻 Scenedesmus bijuga }(0.031) \\
\text { 四尾栅藻 Scenedesmus quadricauda }(0.031) \\
\text { 微小四角藻 Tetraedron minimum }(0.031) \\
\text { 小球藻属 Chlorella }(0.031) \\
\text { 啮蚀隐藻 Cryptomonas erosa }(0.031)\end{array}$ & $\begin{array}{l}\text { 伪鱼腥藻属 Pseudanabaena }(0.528) \\
\text { 小环藻属 Cyclotella }(0.100) \\
\text { 螺旋藻属 Spirulina }(0.080) \\
\text { 卵形隐藻 Cryptomonas ovata }(0.040) \\
\text { 点形平裂藻 Merismopedia punciata }(0.027)\end{array}$ & $\begin{array}{l}\text { 伪鱼腥藻属 Pseudanabaena }(0.473) \\
\text { 链形小环藻 Cyclotella catenata }(0.089) \\
\text { 颗粒直链藻 Melosira granulate }(0.048) \\
\text { 束丝藻属 Aphanizomenon }(0.041) \\
\text { 卵形隐藻 Cryptomonas ovata }(0.034) \\
\text { 尖针杆藻 Synedra acus }(0.034) \\
\text { 拟浮丝藻属 Planktothricoides }(0.034) \\
\text { 螺旋藻属 Spirulina }(0.034) \\
\text { 直角十字藻 Crucigenia rectangularis }(0.027) \\
\text { 新月藻属 Closterium }(0.021) \\
\text { 裸甲藻属 } \operatorname{Cymnodimium~}(0.021)\end{array}$ \\
\hline 冬季 & $\begin{array}{l}\text { 具尾蓝隐藻 Chroomonas caudata }(0.372) \\
\text { 小环蕚属 Cyclotella }(0.128) \\
\text { 微芒藻 Micractinium sp. }(0.128) \\
\text { 钟形裸甲藻 Gymnodimium mitratum }(0.128) \\
\text { 颗粒直链藻 Melosira granulate }(0.047) \\
\text { 小球藻属 Chlorella }(0.047) \\
\text { 尖针杆藻 Synedra acus }(0.023) \\
\text { 桥弯藻属 Cymbella }(0.023)\end{array}$ & $\begin{array}{l}\text { 具尾蓝隐藻 Chroomonas caudata }(0.250) \\
\text { 小环藻属 Cyclotella }(0.150) \\
\text { 卵形隐藻 Cryptomonas ovata }(0.125) \\
\text { 小球藻属 Chlorella }(0.100) \\
\text { 韦斯藻属 Westella botryoides }(0.100) \\
\text { 针杆藻属 Synedra }(0.075) \\
\text { 舟形藻属 Navicula }(0.075) \\
\text { 四尾栅藻 Scenedesmus quadricauda }(0.050)\end{array}$ & $\begin{array}{l}\text { 卵形隐藻 Cryptomonas ovata }(0.375) \\
\text { 具尾蓝隐藻 Chroomonas caudata }(0.291) \\
\text { 拟浮丝藻属 Planktothricoides }(0.167) \\
\text { 小环澡属 Cyclotella }(0.125) \\
\text { 螺旋纤维藻 Ankistrodesmus spiralis }(0.042)\end{array}$ \\
\hline
\end{tabular}

* 括号里数据为优势度.

\section{3 浮游植物优势种的营养动力学}

2.3.1 N 添加的藻类生长动力学 具尾蓝隐藻培养周期为 $12 \mathrm{~d}$, 在 $\mathrm{N}$ 添加浓度为 $0.2 \mathrm{mg} / \mathrm{L}$ 时, 开始对藻生长有 促进作用, 在 $\mathrm{N}$ 添加浓度为 $3.2 \mathrm{mg} / \mathrm{L}$ 以上时达到最大生物量; 链形小环藻培养周期为 $10 \mathrm{~d}, \mathrm{~N}$ 添加浓度在 1.6 $\mathrm{mg} / \mathrm{L}$ 时只生长到第 $6 \mathrm{~d}$ 便持续减少, 在 $\mathrm{N}$ 添加浓度为 $3.2 \mathrm{mg} / \mathrm{L}$ 以上时达到最大生物量; 伪鱼腥藻培养周期为 $8 \mathrm{~d}$, 其生长周期比其他两种藻要短, 在前 $3 \mathrm{~d}$ 处于适应期, $\mathrm{N}$ 浓度在 $0.8 \mathrm{mg} / \mathrm{L}$ 时开始对生长有促进作用, 随着 


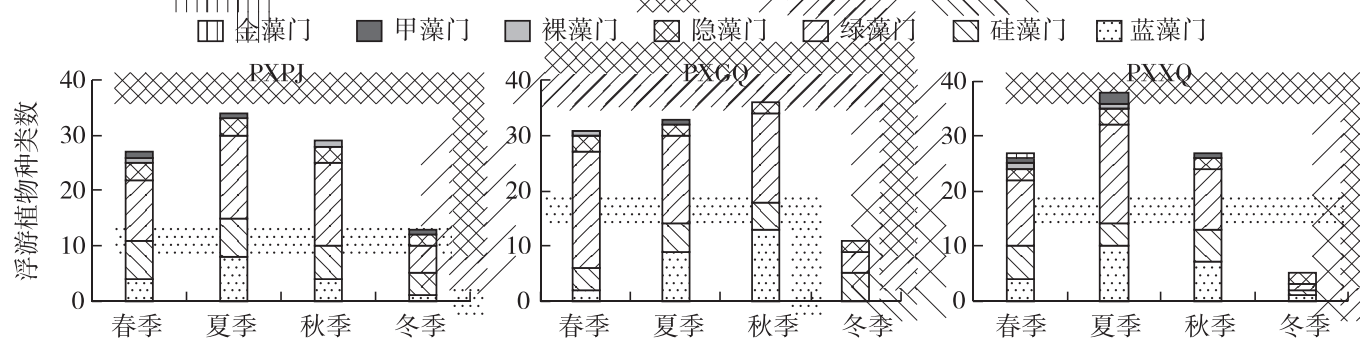

图 23 个湖泊不同季节浮游植物的种类分布

Fig.2 Seasonal distributions of phytoplankton taxa in the three lakes

$\mathrm{N}$ 浓度的增加生物量呈非常快速的趋势, $\mathrm{N}$ 浓度为 $12.8 \mathrm{mg} / \mathrm{L}$ 时, 其生物量达到最大, $2 \mathrm{~d}$ 便达到稳定期(图 3 ).
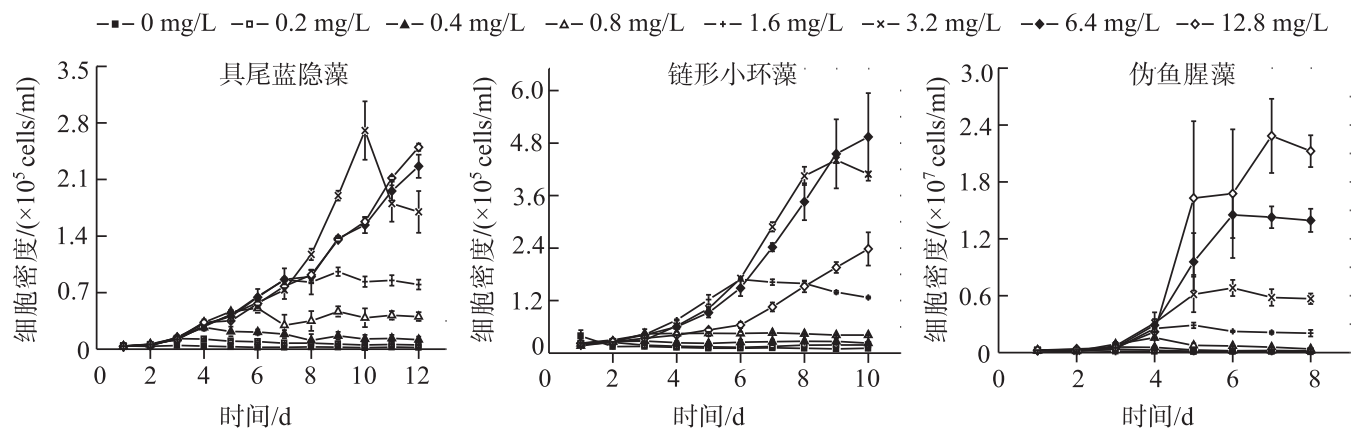

图 3 不同 $\mathrm{N}$ 浓度下具尾蓝隐藻、链形小环藻和伪鱼腥藻的生长曲线

Fig.3 Growth of Chroomonas caudate, Cyclotella catenata and Pseudanabaena sp. with different N concentrations

3 种藻类比生长速率对 $\mathrm{N}$ 营养添加有很好的响应, $1 / c$ 与 $1 / \mu$ 线性回归方程及根据其确定的 $\mu_{\max }$ 和 $K s$ 如图 4 所示, 其中伪鱼腥藻和具尾蓝隐藻 $\mu_{\max }$ 较大, 分别为 0.71 和 $0.66 \mathrm{~d}^{-1}$, 而链形小环藻较小, 为 $0.37 \mathrm{~d}^{-1}$. 伪鱼腥藻 $K s$ 最大, 为 $2.26 \mathrm{mg} / \mathrm{L}$, 链形小环藻 $K s$ 最小, 为 $1.06 \mathrm{mg} / \mathrm{L}$.
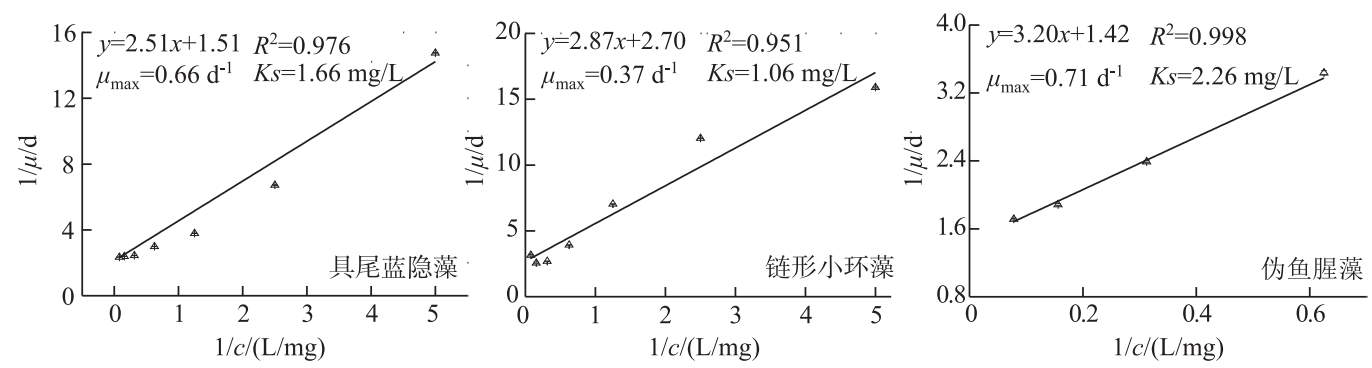

图 43 种藻类比生长速率与 $\mathrm{N}$ 浓度的线性回归 (由于伪鱼腥藻在 $\mathrm{N}$ 浓度高于 $0.8 \mathrm{mg} / \mathrm{L}$ 时才开始对 $\mathrm{N}$ 添加有较好的响应, 故在 $\mathrm{N}$ 浓度为 $1.6 \mathrm{mg} / \mathrm{L}$ 以上时与比生长率进行线性回归)

Fig.4 The linear regression between specific growth rate and $\mathrm{N}$ concentration forthe three studied species

( The growth of Pseudanabaena sp. started to response to $\mathrm{N}$ addition above $0.8 \mathrm{mg} / \mathrm{L} \mathrm{N}$ and the linear regression was conducted with $\mathrm{N}$ concentrations above $1.6 \mathrm{mg} / \mathrm{L}$ )

2.3.2 $\mathrm{P}$ 添加的藻类生长动力学 3 种藻类对 $\mathrm{P}$ 添加均有很好的响应, 即培养期间藻类生物量随着 $\mathrm{P}$ 浓度的 添加呈增加趋势. 其中具尾蓝隐藻在第 $12 \mathrm{~d}$ 达到最大藻密度; 链形小环藻在第 $10 \mathrm{~d}$ 达到最大藻密度; 伪鱼腥 藻在第 $8 \mathrm{~d}$ 达到最大藻密度(图 5). 


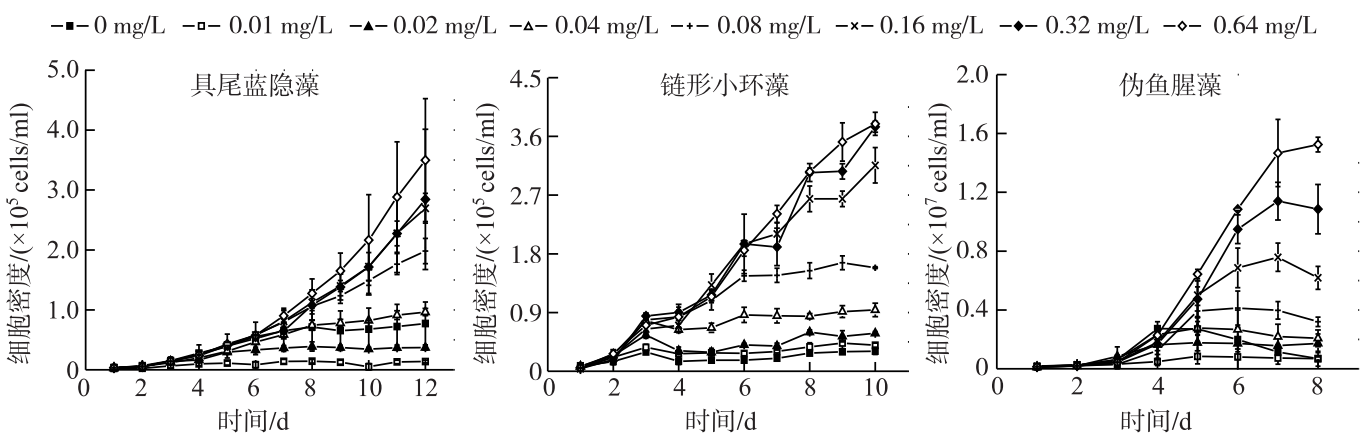

图 5 不同 $\mathrm{P}$ 浓度下具尾蓝隐藻、链形小环藻和伪鱼腥藻的生长曲线

Fig.5 Growth of Chroomonas caudata, Cyclotella catenata and Pseudanabaena sp. with different P concentrations

$1 / c$ 与 $1 / \mu$ 线性回归方程及根据其确定的 $\mu_{\text {max }}$ 和 $K s$ 如图 6 所示, 其中伪鱼腥藻的 $\mu_{\max }$ 最大, 为 $0.90 \mathrm{~d}^{-1}$, 而链形小环藻较小, 为 $0.31 \mathrm{~d}^{-1}$. 伪鱼腥藻的 $K s$ 最小, 为 $0.015 \mathrm{mg} / \mathrm{L}$, 链形小环藻的 $K s$ 最大, 为 $0.035 \mathrm{mg} / \mathrm{L}$.
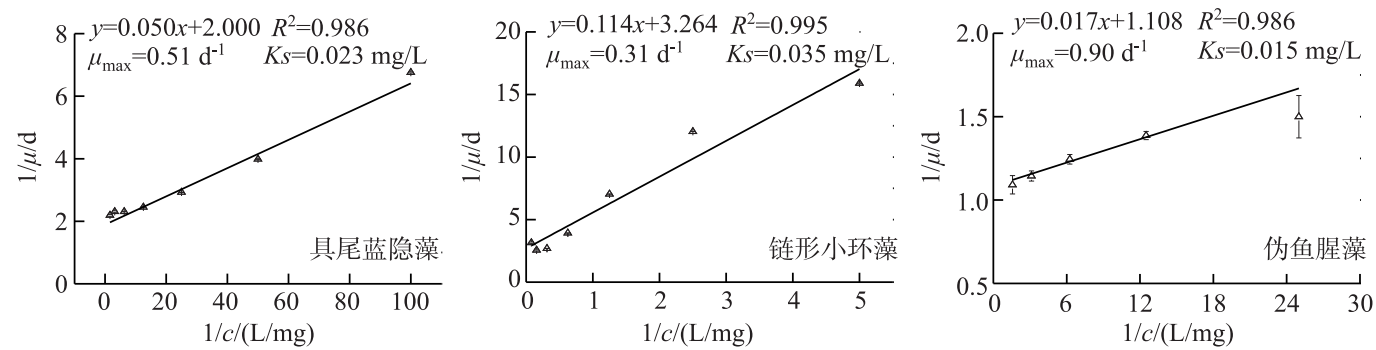

图 63 种藻类比生长速率与 $\mathrm{P}$ 浓度的线性回归

Fig.6 The linear regression between specific growth rate and P concentration for the three studied species

\section{3 讨论}

影响浮游植物群落结构的因素有物理、化学和生物等因子, 即通常受到 “上行效应” 和 “下行效应” 两种 机制调控,在具体水环境中, 不同因子在不同生态系统中都有可能成为控制浮游植物生长、群落结构组成与 演替的关键因素 ${ }^{[13-14]}$. 本文研究 4 个季节 3 个湖泊的营养状态指数分别为 52 61、56 70 和 49 59, 总体处 于轻度一中度富营养化状态, 在富营养湖泊中, 由于浮游植物粒径较大, 特别是群体聚集性藻的生物可食性 较弱, 从而可能导致“下行效应” 不足而 “上行效应” 更为突出 ${ }^{[15]}$, 即营养盐、光照和温度等对浮游植物群落 结构组成有更突出的影响.

调查期间, 3 个塌陷湖泊除 PXXQ 站点冬季 TP 浓度外, 其余各站点各季度的氮、磷浓度均超出 III类水质 标准, 特别是 PXGQ 站点由于有肥料的投人, 营养盐特别是 P 浓度大幅上升, 春、夏、秋季氮、磷浓度甚至超 过 $\mathrm{V}$ 类水标准. 在富营养化湖泊中, 浮游植物生物量的上升通常会引起光因子限制, 造成耐受低光环境的浮 游植物类群占据优势地位, 3 个湖泊的优势种 (属) 如具尾蓝隐藻、伪鱼腥藻、小环藻以及小球藻等物种均具 有对弱光环境的耐受特征 ${ }^{[6,16-17]}$. 但由于各湖泊生态水文条件、营养盐比率、渔业活动方式与程度的不同, 浮游植物群落结构存在较大差异. 塌陷湖泊在冬、春季水温较低时隐藻、硅藻类群占据优势地位, 特别是对 牧食压力较为敏感的隐藻类群, 可能是由于水温偏低时捕食者未大量发育而导致其占据第 1 优势地位 (表 $3)^{[6]}$. 夏、秋季水温升高, 浮游植物生物量迅速增加, 适应高温和低光环境 (由浮游植物自遮光效应所产生) 的丝状蓝藻在 PXGQ 和 PXXQ 站点中迅速占据绝对优势地位. 但 PXPJ 站点中仍然以隐藻和硅藻为主要优 势类群, 该湖泊和泥河联通, 和相对封闭的其他两个湖泊可能存在一定的差异, 从而导致浮游植物群落结构 出现不同. 
从浮游植物营养动力学角度来看, $\mu_{\max }$ 为当限制性底物浓度趋向无穷大时生物的生长速率, $K s$ 通常用来 衡量生物物种对营养物质的亲和性, Ks 值越小亲和性越高, 二者综合起来可以分析不同藻类在营养盐竞争 中的优势地位. 如果 $\mu_{\max 1}=\mu_{\max 2}, K s_{1}<K s_{2}$, 那么两种藻在营养较丰富的时候可以共同生长, 互不占优势, 但是 在营养短缺时, 藻 1 可以迅速占优势; 当 $\mu_{\max 1}>\mu_{\max 2}, K s_{1}>K s_{2}$, 那么在营养丰富的时候藻 1 占优势, 而营养短 缺时藻 2 将占优势, 这就是确定最大比增长率和半饱和常数的意义 ${ }^{[18-19]}$.

塌陷湖泊 3 个优势浮游植物种类中, $N$ 限制下具尾蓝隐藻、链形小环藻和伪鱼腥藻的 $\mu_{\max }$ 和 $K s$ 分别为 $0.66 \mathrm{~d}^{-1} 、 1.66 \mathrm{mg} / \mathrm{L} ; 0.37 \mathrm{~d}^{-1} 、 1.06 \mathrm{mg} / \mathrm{L} ; 0.71 \mathrm{~d}^{-1} 、 2.26 \mathrm{mg} / \mathrm{L} ; \mathrm{P}$ 限制下它们的 $\mu_{\max }$ 和 $K s$ 分别为 $0.51 \mathrm{~d}^{-1}$ 、 $0.023 \mathrm{mg} / \mathrm{L} ; 0.31 \mathrm{~d}^{-1} 、 0.035 \mathrm{mg} / \mathrm{L} ; 0.90 \mathrm{~d}^{-1} 、 0.015 \mathrm{mg} / \mathrm{L}$. 从中可以看出, 链形小环藻比具尾蓝隐藻和伪鱼腥 藻具有更强的 $\mathrm{N}$ 亲和性, 因此在 $\mathrm{N}$ 营养相对缺乏情况下, 链形小环藻对资源竞争能力更强, 而在 $\mathrm{N}$ 营养丰富 的情况下, 伪鱼腥藻能够形成优势, 有研究表明丝状蓝藻对高浓度 $\mathrm{N}$ 的适应性 ${ }^{[20]}$. 同时伪鱼腥藻比具尾蓝 隐藻和链形小环藻具有更强的 P 亲和性, 因此在 P 营养相对缺乏的情况下, 伪鱼腥藻更容易在 P 竞争中取 得优势地位.

此前相关研究表明, 由于农业非点源的大量输人, 淮南塌陷湖泊 $\mathrm{N}$ 相对丰富, 水体初级生产主要受 P 限 制 ${ }^{[8]}$, 结合实际水环境调查结果 (表 2)、浮游植物群落结构 (表 3) 和各优势种营养动力学参数可知, 在 3 个 湖泊 $\mathrm{N}$ 浓度相差不大、但存在 $\mathrm{P}$ 限制的环境条件下, 伪鱼腥藻 $\mu_{\max }$ 最大而 $K s$ 值最低, 对 $\mathrm{P}$ 亲和性最强, 形成 优势, 同时耐受高温并适应低光环境 ${ }^{[21]}$, 因而夏、秋季在 PXGQ 和 PXXQ 站点中占据优势地位. 在水温相对 较低的春、冬季, 浮游生物生长缓慢, 特别是丝状蓝藻对温度较为敏感, 而隐藻对 $\mathrm{P}$ 的 $K s$ 值低于链形小环 藻, $\mu_{\text {max }}$ 大于链形小环藻, 且水体中的 $N$ 浓度与隐藻的 $K s$ 值最为接近, 这些综合因素使得隐藻容易成为优势 种. PXPJ 站点与其他两个站点相比, 硅藻和隐藻类群常年占优势, 原因可能在于 PXPJ 站点与河流相通, 有 硅的输人, 同时还可能与水环境条件、浮游动物和滤食性鱼类有关, 具体原因需要进一步深人研究. 此外, 后 续研究还需要综合营养、光照、温度及生物等多重因子的影响, 建立相关的生态动力学模型, 进一步确认并 量化浮游植物群落结构演替的主要因素和动力学机制 ${ }^{[22-23]}$.

从塌陷湖泊生态系统和营养盐管理角度上看, 具尾蓝隐藻和链形小环藻蛋白质含量高, 是鱼类和水产 养殖动物的天然饵料, 而伪鱼腥藻则是易暴发水华的典型藻种, 特别是塌陷湖泊氮浓度较高, 在 P 浓度进一 步升高, 加上夏季温度光照适宜的情况下, 可能会导致丝状蓝藻浮游植物密度的急剧攀升引起水华, 事实上 在夏季 PXXQ 和 PXGQ 塌陷湖泊的部分避风区, 已经能见到部分丝状蓝藻的聚集, 值得重点关注. 湖泊的初 级生产力主要受水体中 N $\mathrm{P}$ 浓度及二者比率的影响, 此前相关研究表明, 两淮塌陷湖泊初级生产主要受 P 限制并与湖泊水体 P 浓度呈良好的正相关关系 ${ }^{[8,24]}$, 因而, 要控制湖泊水华的发生, 首要应控制水中 P 的浓 度, 同时 $\mathrm{N}$ 浓度降低也可以减少丝状蓝藻的生物量, 因为其对 $\mathrm{N}$ 的亲和性也较弱. 综合来看, 控制水体中 $\mathrm{TN}$ 浓度在 $2.0 \mathrm{mg} / \mathrm{L} 、 \mathrm{P}$ 浓度在 $0.1 \mathrm{mg} / \mathrm{L}$ ( IV 类水质标准) 能维持水生态环境的健康, 进一步可以优化渔业活动, 保持控制丝状蓝藻的同时促进渔业生产.

\section{4 结论}

1) 2014-2015 年对淮南潘谢矿区 3 个塌陷湖泊的调查期间, 观察到浮游植物共 7 门 51 属 88 种, 其中 PXPJ 站点春季的第 1 优势种 (属) 为尖针杆藻, 夏、秋、冬季分别为具尾蓝隐藻、小环藻和具尾蓝隐藻; PXGQ 站点春、冬季第 1 优势种 (属) 为具尾蓝隐藻, 夏、秋季为伪鱼腥藻; PXXQ 站点春季第 1 优势种 (属) 为具尾 蓝隐藻, 夏、秋季为伪鱼腥藻, 冬季为卵型隐藻.

2) 从浮游植物营养动力学角度上看, 链形小环藻比具尾蓝隐藻和伪鱼腥藻具有更强的 $N$ 亲和性, 因此 在 N 营养相对缺乏情况下更容易在竞争中取得优势; 在塌陷湖泊现阶段 N 营养丰富 P 相对缺乏的环境条件 下, 伪鱼腥藻具有比具尾蓝隐藻和链形小环藻更强的 P 亲和性, 加上丝状蓝藻的其他生态学特征, 使得其易 于在夏、秋季形成优势类群. 结合区域营养状况和初级生产限制条件,在塌陷湖泊营养管理中 P 的控制和调 节十分重要.

\section{5 参考文献}

[ 1 ] Yi QT, Sun PF, Xie K et al. Impact of regional water chemistry on the phosphorus isothermal adsorption of the sediments 
in three subsidence waters of the Huainan mine areas. Environmental Science, 2013, 34(10): 3894-3903. [易齐涛, 孙 鹏飞, 谢凯等. 区域水化学条件对淮南采煤沉陷区水域沉积物磷吸附特征的影响研究. 环境科学, 2013, 34(10) : 3894-3903.]

[ 2 ] Deng DG, Xing RL, Ma R et al. Seasonal variations on community structure of crustacean zooplankton in a small lake of an excavating coal subsidence region in Huaibei City. J Lake Sci, 2010, 22(4) : 591-597. DOI: 10.18307/2010.0417. [邓道 贵, 邢荣龙, 马点等. 淮北采煤塌陷区小型湖泊浮游甲壳动物群落结构的季节变化. 湖泊科学, 2010, 22(4): 591-597.]

[ 3 ] Xu X, Yi QT, Wang XM et al. Phytoplankton community in the small subsided lakes around Huainan coal mine subsidence areas. Acta Hydrobiologica Sinica , 2015, 39(4) : 740-750. [ 徐金金, 易齐涛, 王晓萌等. 淮南矿区小型煤矿塌陷湖 泊浮游植物群落结构特征. 水生生物学报, 2015, 39(4): 740-750.]

[ 4 ] Deng DG, Meng XL, Lei J et al. Community structure and seasonal dynamics of phytoplankton in small lakes of Huaibei excavating coal subsidence region. Ecological Science, 2010, 29(6) : 499-506. [邓道贵, 孟小丽, 雷娟等. 淮北采煤塌 陷区小型湖泊浮游植物群落结构和季节动态. 生态科学, 2010, 29(6) : 499-506.]

[ 5 ] Wang XM, Yi QT, Xu X et al. Rotifer communities in the small lakes around Huainan coal mine subsidence areas. J Lake $S c i, 2015,27$ (4) : 657-666. DOI: 10.18307/2015.0414. [王晓萌, 易齐涛, 徐金等. 淮南采煤沉陷区内小型塌陷湖 泊轮虫群落结构特征. 湖泊科学, 2015, 27(4) : 657-666.]

[ 6 ] Yi QT, Chen QW, Zhao DH et al. Seasonal succession of phytoplankton functional groups and their driving factors in the artificial lakes created by mining subsidence in Huainan coal mine areas. Acta Ecologica Sinica, 2016, 36 (15) : 48434854. [易齐涛, 陈求稳, 赵德慧等. 淮南采煤塌陷湖泊浮游植物功能群的季节演替及其驱动因子. 生态学报, 2016, 36(15) : 4843-4854.]

[ 7 ] Yin H ed. Compilation of standards for environmental monitoring methods: Water environment. Beijing: Standards Press of China, 2007. [尹航. 环境监测方法标准汇编: 水环境. 北京: 中国标准出版社, 2007.]

[ 8 ] Wang TT, Yi QT, Hu YB et al. Eutrophication and nutrient enrichment bioassays in the waters of the Huainan and Huaibei coal mining subsidence areas, Anhui Province. J Lake Sci, 2013, 25(6) : 916-926. DOI: 10.18307/2013.0616. [王婷 婷, 易齐涛, 胡友彪等. 两淮采煤沉陷区水域水体富营养化及氮、磷限制模拟实验. 湖泊科学, 2013, 25(6): 916-926.]

[ 9 ] Qu XJ, Yi QT, Hu YB et al. Nutrient spatiotemporal distribution and eutrophication process in subsidence waters of Huainan and Huaibei mining areas, China. Chinese Journal of Applied Ecology, 2013, 24(11): 3249-3258. [曲喜杰, 易齐 涛, 胡友彪等. 两淮采煤沉陷积水区水体营养盐时空分布及富营养化进程. 应用生态学报, 2013, 24(11): 3249-3258.]

[10] Zhang ZS, Huang XF eds. Freshwater plankton research methods. Beijing: Science Press, 1991:36-37. [章宗涉, 黄祥 飞. 淡水浮游生物研究方法. 北京: 科学出版社, 1991: 36-37.]

[11] National Eutrophication Survey ed. Code for investigation of lake eutrophication. Beijing: China Environmental Science Press, 1990. [全国富营养化调查组. 湖泊富营养化调查规范. 北京: 中国环境科学出版社, 1990.]

[12] Zhang ZJ ed. Activated sludge biology and reaction kinetics. Beijing: China Environmental Science Press, 1989: 355-356. [张自杰. 活性污泥生物学与反应动力学. 北京: 中国环境科学出版社, 1989: 355-356. ]

[13] Litchman E, Pinto PDT, Klausmeier CA et al. Linking traits to species diversity and community structure in phytoplankton. Hydrobiologia , 2010, 653(1): 15-28.

[14] Cellamare M, Pinto PDT, Leitão M et al. Using functional approaches to study phytoplankton communities in a temperate region exposed to tropical species dispersal. Hydrobiologia, 2013, 702(1) : 267-282.

[15] Kalff J ed. Limnology: Inland water ecosystem. Beijing: Higher Education Press, 2011: 334-335. [Kalff J. 湖沼学: 内陆 水生生态系统. 北京: 高等教育出版社, 2011: 334-335.]

[16] Reynolds CS, Huszar V, Kruk C et al. Towards a functional classification of the freshwater phytoplankton. Journal of Plankton Research, 2002, 24(5): 417-428.

[17] Padisák J, Crossetti LO, Naselli-Flores L. Use and misuse in the application of the phytoplankton functional classification : A critical review with updates. Hydrobiologia. 2009, 621 (1): 1-19.

[18] Zheng SF, Yang SW, Jin XC. Dynamic studies on the effect of nutrients on the growth of Microcystis aeruginosa. Environmental Science, 2005, 26(2) : 152-156. [郑朔方, 杨苏文, 金相灿. 铜绿微囊藻生长的营养动力学. 环境科学, 
$2005,26(2): 152-156$.

[19] Wang WJ, Yao D, Zhao CH et al. Influence of nitrogen and phosphorus on growth of four filamentous cyanobacteria strains in freshwater. Ecological Science, 2008, 27 (4) : 202-207. [王文杰, 姚旦, 赵辰红等. 氮磷营养盐对四种淡水丝状蓝 藻生长的影响.生态科学, 2008, 27(4) : 202-207.]

[20] Cheng HM, Qiu BS. Cyanobacterial gas vesicles and their regulation on the vertical distribution of cyanobacteria in water body. Plant Physiology Communications, 2006, 42 (5) : 974-980. [成慧敏, 邱保胜. 蓝藻的伪空泡及其对蓝藻在水体 中垂直分布的调节. 植物生理学报, 2006, 42(5): 974-980.]

[21] Xu H, Yang LZ, Mao H et al. Dynamic studies on the effect of phosphorus on the growth of Microcystis aeruginosa and Scendesmus obliquus. Ecology and Environment Sciences, 2006, 15(5): 921-924. [许海, 杨林章, 茅华等. 铜绿微囊 藻、斜生栅藻生长的磷营养动力学特征. 生态环境学报, 2006, 15(5) : 921-924.]

[22] Nicklisch A, Shatwell T, Köhler J. Analysis and modelling of the interactive effects of temperature and light on phytoplankton growth and relevance for the spring bloom. Journal of Plankton Research, 2008, 30: 75-91.

[23] Mieleitner J, Borsuk M, Brgi HR et al. Identifying functional groups of phytoplankton using data from three lakes of different trophic state. Aquat Sci, 2008, 70: 30-46.

[24] Yi QT, Xu X, Qu XJ et al. Characterization of primary productivity in the aquatic zones around the Huainan and Huaibei coalmine subsidence areas. China Environmental Science, 2014, 34(8) : 2101-2110. [易齐涛, 徐釒金, 曲喜杰等. 两淮 采煤沉陷积水区水体初级生产特征. 中国环境科学, 2014, 34(8): 2101-2110.] 